\title{
Linkage between International Food Commodity Prices and the Chinese Stock Markets
}

\author{
Jin-Su Kang ${ }^{1}$, Jin-Li Hu ${ }^{1} \&$ Ching-Wen Chen ${ }^{1}$ \\ ${ }^{1}$ Institute of Business and Management, National Chiao Tung University. No. 118, Sec. 1, Chung-Hsiao W. Rd., \\ Taipei City 100, Taiwan \\ Correspondence: Jin-Li Hu, Institute of Business and Management, National Chiao Tung University, 118, \\ Chung-Hsiao W. Rd., Taipei City 10044, Taiwan. Tel: 886-2-2349-4922. E-mail: jinlihu@gmail.com
}

Received: July 11, 2013

Accepted: August 14, 2013 Online Published: September 26, 2013

doi:10.5539/ijef.v5n10p147

URL: http://dx.doi.org/10.5539/ijef.v5n10p147

\begin{abstract}
This study examines causal relationships between international food commodity prices and daily stock indices in China, including Shanghai Stock Exchange (SSE) and Shenzhen Stock Exchange (SZSE), during 2000-2010. The empirical results show that both China's stock indices have bilateral Granger causality relationships with international food commodity futures including wheat, corn, soybean, and soybean oil, while rough rice is found to have a unilateral Granger causal relationship with these stock indices. The study further extends to examine the impulse-response analysis among Granger causal relationships and both positive and negative responses are found. The stock price indices have negative responses to the increase of food future prices, while food future prices have positive responses to the increase of China's stock indices.
\end{abstract}

Keywords: food commodity price, Chinese stock index, granger causality, impulse-response analysis

\section{Introduction}

Recent studies indicate that the increased frequency of heat stress, droughts, and floods negatively affects crop yields and livestock beyond the impacts of a mean climate change, creating the possibility for surprises, with impacts that are larger, and occurring earlier, than predicted using changes in mean variables alone (IPCC, 2007). Recently, the worst heat wave in over a millennium last summer destroyed 40\% of Russia's 2010 crop harvest, leading to a ban on the export of all grains. This disaster alone has had a significant global impact on food prices as Russia is the world's third largest exporter of wheat. In June 2011 the worst flooding over the last 56 years in China cut vegetable production by $20 \%$ and displaced 5 million people. Corn prices are set to sky-rocket as a result. These natural disasters thus create uncertainties to agricultural production, leading to increasing volatility in food commodity prices. Moreover, huge demand from Asia, such as China and India, are pushing up food commodity prices higher and contributing to increasing the volatility.

A number of studies indicate that these volatile food prices affect developing countries more than developed countries (Diouf, 2007; Rosegrant, 2008). Among developing countries, food prices are of particular importance to China, because it is the one of the largest producers and consumers. Since expenditure on food in China makes up more than $30 \%$ of budgets, any substantial price increase in food almost certainly has implications for overall price stability (Yang et al., 2008). Domestic prices of food commodities are also significantly affected by international prices, because of no restriction on food trade across China's borders (Rosen et al., 2004; Huang et al., 2008). On the other hand, previous studies regarding the food commodity market mostly deal with its volatility such as the spillover effect of crude oil prices (Babula \& Somwaru, 1992; Uri, 1996; Du et al., 2009) and modeling and forecasting (Fama \& French, 1987; Onour \& Sergi, 2011). While a few studies present empirical support for correlations between food commodities and a stock index (Siqueira et al. 2010; Johnson and Soenen 2009), not much has been known about the impacts of international food commodity prices on Chinese firms, which are a part of the world's largest player in the global food market.

Motivated by this gap, this study intends to investigate the relationship between international food commodity future prices and the return of daily stock indices in China, including Shanghai Stock Exchange (SSE) and Shenzhen Stock Exchange (SZSE). We employ the daily data of five international food commodity futures, namely wheat, corn, soybean, soybean oil, and rough rice as well as Chinese stock exchanges from January 1, 2000, to December 31, 2010. 
Our findings show that there exist bilateral Granger cause relationships between most of the food futures prices and both stock indices except for rough rice. Both stock indices show negative responses to the increase in food futures prices, including wheat, corn, soybean, and soybean oil, while all food futures prices show positive responses to the increase in stock price indices.

The following section addresses brief literature review on the relationship between futures and stock indices. Then, methodology and results show the procedures taken in these analyses and their application to the data, respectively, leading to the conclusion of the study.

\section{Brief Literature Review}

This study is indebted to a number of literatures on the relationship between futures and stock indices (Finnerty \& Park, 1987; Kawaller et al., 1987; Ng, 1987; Harris, 1989; Stoll \& Whaley, 1990; Chan, 1992; Tse, 1999). Finnerty and Park (1987) show a significant relationship between the change in futures prices and the subsequent change in the stock index with intraday spot and futures prices of the Chicago Board of Trade's Major Market Index (MMI) and the Maxi Major Market Index (MMMI). Other scholars focus on the lead-lag relationship between futures prices and stock index. Kawaller et al. (1987) note that movement in S\&P 500 futures prices consistently lead movement in the S\&P 500 index by twenty to forty-five minutes, while for the other way around it rarely extends beyond one minute. $\mathrm{Ng}$ (1987) finds that futures returns generally lead spot returns for a variety of futures contracts, including the S\&P 500 index. Stoll and Whaley (1990) investigate the time series of five-minute, intraday returns of stock index and stock index futures contracts. The research shows that S\&P 500 and Major Market Index (MM Index, the trading symbol is known as XMI now) futures returns tend to lead stock market returns by about five minutes in general, but occasionally do so for over ten minutes or longer. Chan's (1992) finding from lead-lag relation between MM cash index and MM Index and S\&P 500 futures shows that as more stocks move together implying market-wide information, the futures lead the cash index to a greater degree. This suggests that the futures market is the main source of market-wide information as well.

The lead-lag relationship exists in commodity futures and spot markets as well. Fama and French (1987) find both direct and indirect evidence to support the forecasting power of the futures prices on commodities based on 21 commodities during 1965-1984. Gorton and Rouwenhorst (2004) show that commodity future returns are negatively correlated with equity and bond returns. Their finding also shows that commodity futures are positively correlated with inflation, unexpected inflation, and changes in expected inflation.

In addition, China is seriously influenced by changes of world food prices from two aspects: (i) In China, expenditure on food makes up nearly $36 \%$ of urban budgets and more than $43 \%$ of rural budgets (NBSC, 2007). Therefore, any substantial price increase in food almost certainly has implications for overall price stability (Yang et al., 2008); and (ii) Domestic prices of food commodities are also significantly affected by international prices, because of no restriction on food trade across China's borders (Rosen et al., 2004; Huang et al., 2008). Thus, Yang et al. (2008) find that domestic prices of soy and other oilseeds have risen with international prices due to a lack of policy instruments for soybeans.

Based on the aforementioned literature, we expect bilateral relationship between international food commodity futures and Chinese stock indices. International food prices influence Chinese food price affecting on Chinese economy reflected on the stock indices, as any economic changes (i.e., stock indices) in China influence domestic demand of food affecting on world food prices because China is the one of the largest producers and consumers. For this purpose, we utilize both Granger-causality and impulse-response tests, which are introduced in the following section.

\section{Methodology}

A time series variable can be divided into being stationary or non-stationary. A stationary time series variable is one whose statistical properties, such as mean, variance, autocorrelation, etc., are all constant over time. This can be tested by a unit root test using an autoregressive model. The most common methods applied are augmented the Dickey-Fuller $(1979,1981)$ (ADF) test and the Phillips-Perron (1988) (PP) test. Both tests use the existence of a unit root as the null hypothesis.

If times series are non-stationary with unit roots, they must be made stationary by means of a difference filter before carrying out Granger causality tests. It is supposed that variable $X_{t}$ Granger causes $Y_{t}$, if the predication of the current value of $Y_{t}$ is improved by including past values of $X_{t}$. The Granger $(1974,1981)$ test is mainly based on the concept of 'predictability' when evaluating the casual relationship between variables, or specifically a lead or laggard relation between variables. 


\subsection{Granger Causality Test}

In this study we apply Hsiao's (1981) version of the Granger causality test between two stationary variables, $X_{t}$ and $Y_{t}$. Hsiao's (1981) procedure combines the Akaike (1969)'s final prediction error (FPE) criterion with Granger's causality test. If two variables are tested to be stationary, the standard form of Granger causality approach can be expressed as follows:

$$
\begin{gathered}
\Delta Y_{t}=\alpha+\sum_{i=1}^{P} \beta_{i} \Delta Y_{t-i}+u_{1 t} \\
\Delta Y_{t}=\alpha+\sum_{i=1}^{P} \beta_{i} \Delta Y_{t-i}+\sum_{j=1}^{Q} \gamma_{j} \Delta X_{t-j}+u_{2 t}
\end{gathered}
$$

where $\alpha$ is a constant term, $\beta$ and $\gamma$ are coefficients of exogenous variables, and $u_{1 t}$ and $u_{2 t}$ are white noise error terms. Hsiao's (1981) step consists of two steps. First, FPE $(p)$ is computed with an order of lags $i$ varying from 1 to $P$ in Equation (1) by the following equation:

$$
\operatorname{FPE}(p)=\left(\frac{T+p+1}{T-p-1}\right)\left(\frac{S S E}{T}\right)
$$

where $T$ denotes the number of observations and sum of squared errors (SSE) is the sum of squared errors. The minimum FPE ( $p$ ) decides the optimal lag $p^{*}$. Then, in Equation (2), SSE of $Y_{t}$ is estimated by altering the lag order, $j$, of $X_{t}$ from 1 to $Q$ as follows:

$$
\operatorname{FPE}\left(p^{*}, q\right)=\left(\frac{T+p^{*}+q+1}{T-p^{*}-q-1}\right)\left(\frac{\operatorname{SSE}\left(p^{*}, q\right)}{T}\right)
$$

The smallest FPE $\left(p^{*}, q\right)$ decides the optimal lag $\left(q^{*}\right)$. If FPE $\left(p^{*}, q^{*}\right)<\operatorname{FPE}\left(p^{*}\right)$, then $X_{t}$ Granger causes $Y_{t}$.

\subsection{Vector Auto Regression Model (VAR)}

Once the Granger causal relationship between variables is identified, this study further examines the dynamic analysis of vector autoregressive (VAR) models using the orthogonalized responses. First, the VAR equations can be rewritten as follows:

$$
\begin{aligned}
& Y_{t}-\sum_{i=1}^{m} \beta_{i} Y_{t-i}=\alpha+\varepsilon_{t} \\
& \left(1-\beta_{1} L-\beta_{2} L^{2}-\ldots-\beta_{m} L^{m}\right) Y_{t}=\alpha+\varepsilon_{t} \\
& Y_{t}=\left(1-\beta_{1} L-\beta_{2} L^{2}-\ldots-\beta_{m} L^{m}\right)^{-1} \alpha+\left(1-\beta_{1} L-\beta_{2} L^{2}-\ldots-\beta_{m} L^{m}\right)^{-1} \varepsilon_{t} \\
& Y_{t}=\alpha^{\prime}+\sum_{i=0}^{\infty} C_{i} \varepsilon_{t-i}
\end{aligned}
$$

where $L$ stands for the lag operator; $\alpha^{\prime}$ stands for $n \times 1$ vector of constants; $C_{i}$ stands for $n \times n$ matrices, and $C_{0}=\mathrm{I}$ stands for a unit matrix.

We next apply the Cholesky decomposition, a practical implementation to generate triangular orthogonalized matrices, to obtain impulse response functions as follows:

Let $C_{t}^{*}=C_{i} K$ and $e_{t-i}=K^{-1} \varepsilon_{t-i}$.

$$
Y_{t}=\alpha^{\prime}+\sum_{i=0}^{\infty} C_{i} K K^{-1} \varepsilon_{t-i}
$$

The above equation can be rewritten as:

$$
Y_{t}=\alpha^{\prime}+\sum_{i=0}^{\infty} C_{i}^{*} e_{t-i}
$$

where $C_{t}^{*}$ is an impact multiplier and $e_{t-1} \mathrm{~s}$ are neither auto-correlated nor contemporaneously correlated. This procedure generates the orthgonalized impulse response functions so that we can investigate how a variable responds to a shock from the other variable.

\subsection{Data Sources}

We utilize the data of five food commodity futures with Chinese stock exchanges including wheat, corn, soybean, soybean oil, and rough rice. For future prices, the daily data from January 1, 2000, to December 31, 2010 of the food commodity futures studied were collected from Chicago Board of Trade (CBOT), the most popular and the first futures and options exchange around the world. CBOT was merged into the Chicago Mercantile Exchange (CME) Group on July 12, 2007. The resulting sample has 2,505 observations, because whole daily data were removed if there was any missing information due to the difference in holidays between China and the U.S. For stock market indices, we employ SSE Composite Index from Shanghai Stock Exchange (SSE) and SZSE Component Index from Shenzhen Stock Exchange (SZSE), because they are the main stock price indices in China. 


\section{Results \& Discussion}

Figure 1 describes the volatility of food commodity futures prices, while Figure 2 shows the volatility of stock market indices. These figures present that both food commodity futures prices and stock market indices reached a peak between 2007 and 2008. The food commodity future prices show an increasing pattern for the last decade with increasing volatility, specifically since the U.S. Financial Crisis. For the case of stock indices, both show a decreasing pattern until 2005, after which they skyrocketed with increasing volatility.
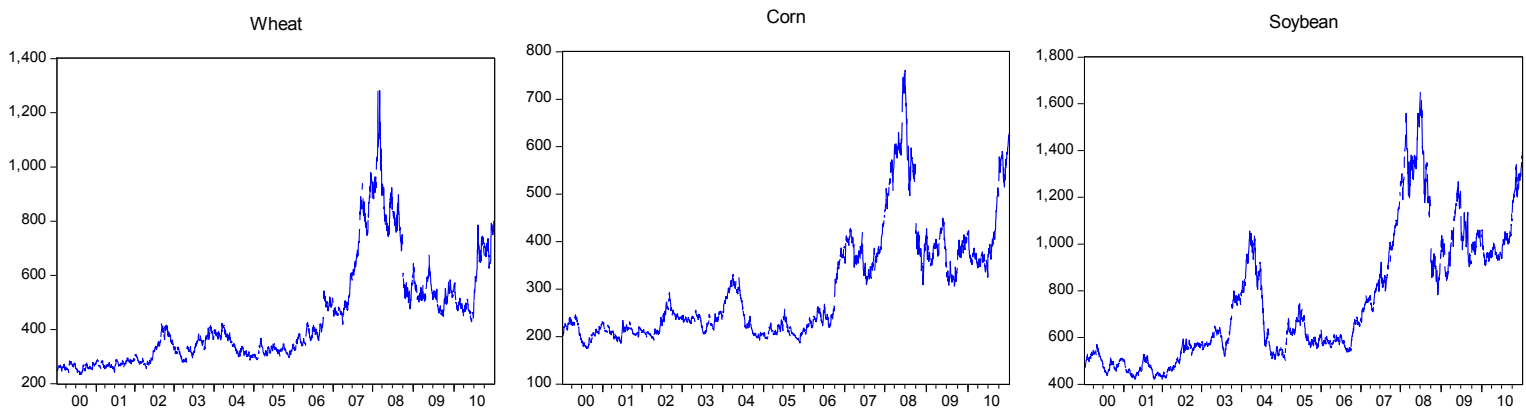

Soybean Oil
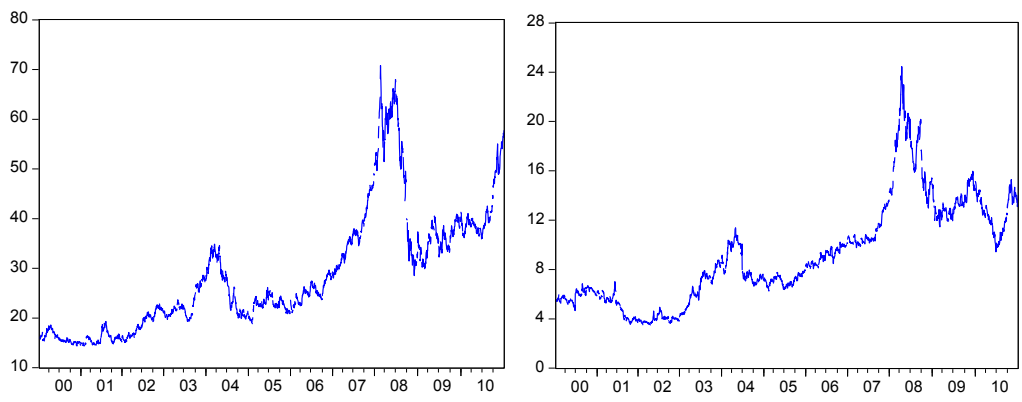

Figure 1. Trends of food futures daily price, with axis $\mathrm{X}$ denoting year and axis $\mathrm{Y}$ denoting price
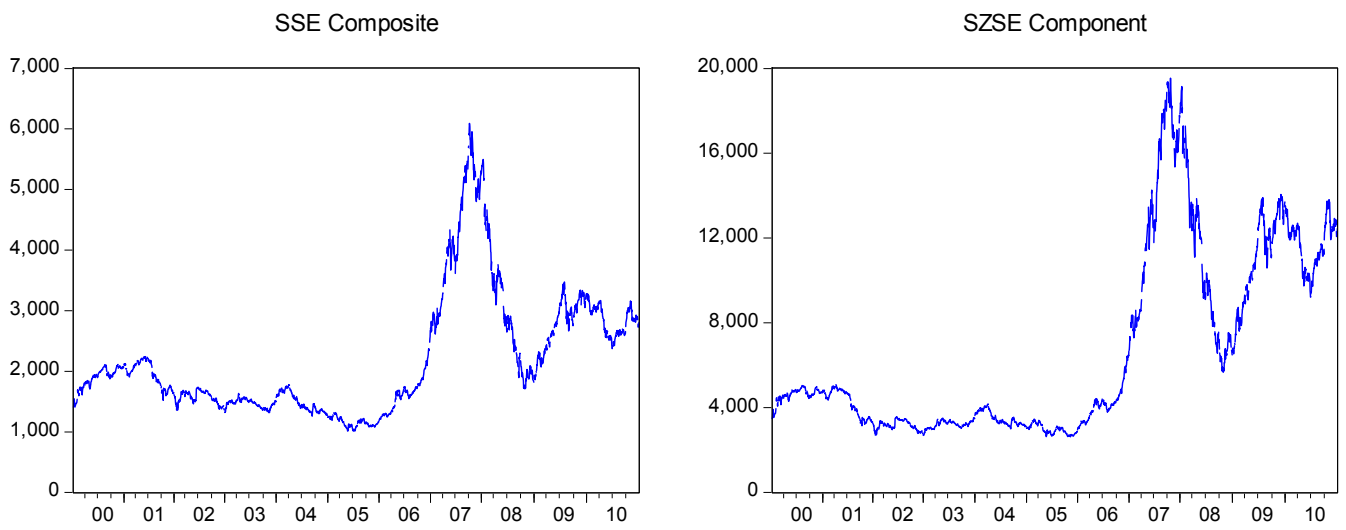

Figure 2. China daily stock price indices, with axis $\mathrm{X}$ denoting year and axis $\mathrm{Y}$ denoting stock price index

To avoid spurious regressions, we run unit root tests by both the augmented Dickey Fuller (ADF) and Phillips-Perron (PP) tests to check if time series variables are non-stationary. Table 1 shows that all of the food futures prices and stock indices are non-stationary in levels. They become stationary after first differencing - that is, they are $\mathrm{I}(1)$ variables. 
Table 1. Results of unit root tests

\begin{tabular}{|c|c|c|c|c|c|c|c|c|}
\hline \multicolumn{2}{|c|}{ Variable } & Wheat & Corn & Soybean & $\begin{array}{l}\text { Soybean } \\
\text { Oil }\end{array}$ & $\begin{array}{l}\text { Rough } \\
\text { Rice }\end{array}$ & $\begin{array}{c}\text { SSE } \\
\text { Composite }\end{array}$ & $\begin{array}{c}\text { SZSE } \\
\text { Component }\end{array}$ \\
\hline \multicolumn{9}{|l|}{ Level } \\
\hline \multirow[t]{3}{*}{$\mathrm{ADF}$} & $P_{u}$ & 0.5781 & 0.8963 & 0.8324 & 0.92 & 0.6662 & 0.6428 & 0.8297 \\
\hline & $P_{t}$ & 0.3 & 0.68 & 0.4914 & 0.7 & 0.3904 & 0.8533 & 0.8003 \\
\hline & $P$ & 0.74 & 0.90 & 0 & 0.937 & 0.7 & 0.6783 & 0.7985 \\
\hline \multirow[t]{3}{*}{ PP } & $P_{u}$ & 0.6292 & 0.8682 & 0 & 0.8825 & 0.636 & 0.6225 & 0.8149 \\
\hline & $P_{t}$ & 0 & 0.59 & 01 & 0.5 & 0.3 & 0.8 & 0.7781 \\
\hline & $P$ & 0.7 & 0 & & 0.9 & 0.7 & 0.6667 & 0.783 \\
\hline \multicolumn{9}{|c|}{ First Difference } \\
\hline \multirow[t]{3}{*}{$\mathrm{ADF}$} & $P_{u}$ & $0.0001^{* * *}$ & $0.0001_{* * * *}^{* *}$ & $0.0001^{* * *}$ & $0.0001^{* * *}$ & $0.0001_{* * * *}^{* * *}$ & $0.0001^{* * * *}$ & $0.0001_{* * * *}^{* * *}$ \\
\hline & $P_{t}$ & $<0.0001^{* * *}$ & $<0.0001^{* * *}$ & $<0.0001^{* * *}$ & $<0.0001^{* * *}$ & $<0.0001^{* * *}$ & $<0.0001^{* * * *}$ & $<0.0001^{* * *}$ \\
\hline & $P$ & $0.0001^{* * *}$ & $0.0001^{* * *}$ & $0.0001^{* * *}$ & $0.0001^{* * *}$ & $0.0001^{* * *}$ & $0.0001^{* * *}$ & $0.0001^{* * *}$ \\
\hline \multirow[t]{3}{*}{ PP } & $P_{u}$ & $0.0001^{* * *}$ & $0.0001^{* * *}$ & $0.0001^{* * *}$ & $0.0001^{* * *}$ & $0.0001^{* * *}$ & $0.0001^{* * *}$ & $0.0001^{* * *}$ \\
\hline & $P_{t}$ & $<0.0001^{* * *}$ & $<0.0001^{* * *}$ & $<0.0001^{* * *}$ & $<0.0001^{* * *}$ & $<0.0001^{* * *}$ & $<0.0001^{* * * *}$ & $<0.0001^{* * *}$ \\
\hline & $P$ & $0.0001^{* * *}$ & $0.0001^{* * *}$ & $0.0001^{* * *}$ & $0.0001^{* * *}$ & $0.0001^{* *}$ & $0.0001^{* * *}$ & $0.0001^{* * *}$ \\
\hline
\end{tabular}

Note: 1$) * * *$ represents significance at the $1 \%$ level.

2) Numbers in this table represent p-value.

3) $\mathrm{Pu}$ and Pt are test equations with intercept and both intercept and linear trend, respectively, while P describes a test equation without intercept and linear trend.

Table 2 explains the descriptive statistics for each first-differenced daily food futures prices and stock indices.

Table 2. Summary of descriptive statistics

\begin{tabular}{lcccc}
\hline \multicolumn{1}{c}{ Variables } & Mean & Std. Dev. & Maximum & Minimum \\
\hline Food commodity & & & & \\
Wheat & 0.2185 & 13.2602 & 90 & -207 \\
Corn & 0.1701 & 7.347 & 36.25 & -119 \\
Soybean & 0.3683 & 16.307 & 70.75 & -242 \\
Soybean Oil & 0.0167 & 0.6023 & 3.68 & -7.4 \\
Rough Rice & 0.0034 & 0.2031 & 1.52 & -2.245 \\
Stock index & & & & \\
SSE Composite & 0.5598 & 49.21 & 304.698 & -620.763 \\
SZSE Component & 3.5789 & 184.0906 & $1,130.61$ & $-2,135.53$ \\
\hline
\end{tabular}

The Granger causality tests are then implemented between stationary variables after first differencing with a lag term of 12 trading days. The results in Table 3 present that a feedback relationship exists among variations of most food futures prices and both stock indices. Except for rough rice, all other commodity futures prices have bilateral Granger causal relationships with both SSE Composite and SZSE Component indices. A unilateral Granger causal relationship exists between rough rice and both stock indices- that is, rough rice does not Granger cause both stock indices. 
Table 3. Results of granger causality test

\begin{tabular}{llll}
\hline Null Hypothesis & F-Statistic & p-value & Result \\
\hline Food commodity futures $v$ s. SSE Composite & & & \\
$\triangle$ WHEAT does not Granger cause $\triangle$ SSE COMPOSITE & 3.6206 & $<0.0001^{* * *}$ & Reject \\
$\triangle$ SSE COMPOSITE does not Granger cause $\triangle$ WHEAT & 4.3596 & $<0.0001^{* * *}$ & Reject \\
$\triangle$ CORN does not Granger cause $\triangle$ SSE COMPOSITE & 3.0497 & $0.0003^{* * *}$ & Reject \\
$\triangle$ SSE COMPOSITE does not Granger cause $\triangle$ CORN & 2.7779 & $0.0009^{* * *}$ & Reject \\
$\triangle$ SOYBEAN does not Granger cause $\triangle$ SSE COMPOSITE & 3.7957 & $<0.0001^{* * *}$ & Reject \\
$\triangle$ SSE COMPOSITE does not Granger cause $\triangle$ SOYBEAN & 2.0954 & $0.0145^{* *}$ & Reject \\
$\triangle$ SOYBEANOIL does not Granger cause $\triangle$ SSE COMPOSITE & 4.9602 & $<0.0001^{* * *}$ & Reject \\
$\triangle$ SSE COMPOSITE does not Granger cause $\triangle$ SOYBEANOIL & 1.5514 & $0.0991^{*}$ & Reject \\
$\triangle$ ROUGHRICE does not Granger cause $\triangle$ SSE COMPOSITE & 1.1426 & 0.3202 & Not reject \\
$\triangle$ SSE COMPOSITE does not Granger cause $\triangle$ ROUGHRICE & 1.9036 & $0.0296^{* *}$ & Reject \\
Food commodity futures vs. SZSE Component & & & \\
$\triangle$ WHEAT does not Granger cause $\triangle$ SZSE COMPONENT & 3.6806 & $<0.0001^{* * *}$ & Reject \\
$\triangle$ SZSE COMPONENT does not Granger cause $\triangle$ WHEAT & 5.2111 & $<0.0001^{* * *}$ & Reject \\
$\triangle$ CORN does not Granger cause $\triangle$ SZSE COMPONENT & 2.5107 & $0.0028^{* * *}$ & Reject \\
$\triangle$ SZSE COMPONENT does not Granger cause $\triangle$ CORN & 3.5215 & $<0.0001^{* * *}$ & Reject \\
$\triangle$ SOYBEAN does not Granger cause $\triangle$ SZSE COMPONENT & 3.3528 & $<0.0001^{* * *}$ & Reject \\
$\triangle$ SZSE COMPONENT does not Granger cause $\triangle$ SOYBEAN & 2.3328 & $0.0057^{* * *}$ & Reject \\
$\triangle$ SOYBEANOIL does not Granger cause $\triangle$ SZSE COMPONENT & 4.4379 & $<0.0001^{* * *}$ & Reject \\
$\triangle$ SZSE COMPONENT does not Granger cause $\triangle$ SOYBEANOIL & 1.7343 & $0.0539^{*}$ & Reject \\
$\triangle$ ROUGHRICE does not Granger cause $\triangle$ SZSE COMPONENT & 1.0828 & 0.3701 & Not reject \\
$\triangle$ SZSE COMPONENT does not Granger cause $\triangle$ ROUGHRICE & 1.6768 & $0.0656^{*}$ & Reject \\
\hline
\end{tabular}

Note: 1$)^{* * * * *},{ }^{*}$ and ${ }^{*}$ represent significance at the $1 \%, 5 \%$, and $10 \%$ levels, respectively. 2 ) $\Delta$ denotes the non-stationary series variable after first-order differences.

This study goes farther to investigate the optimal lag interval between food commodity futures prices and stock indices for Granger causal relationships. First, we examine the optimal lag interval when food futures prices do Granger cause stock indices. The optimal lag interval from wheat to both stock indices is found at 11 trading days, or the same as that from corn to both stock indices. For soybeans, the optimal lag interval turns out to be 6 trading days with the SSE Composite, but 9 trading days with the SZSE Component. The optimal lag interval from soybean oil to both stock indices is 10 trading days.

The optimal lag interval turns out to be different when stock indices do Granger cause food commodity futures prices. The optimal lag intervals from SSE Composite to wheat and corn are 10 and 12 trading days, respectively. Similarly, the optimal lag intervals from SSE Composite to soybean and soybean oil are 10 and 11 trading days, respectively. From SZSE Component, wheat, corn, and soybean oil have 11 trading days, while soybean shows 8 trading days as the optimal lag interval. It is worth noting that the optimal lag interval from both stock indices to rough rice is found at 5 trading days.

Finally, we investigate impulse-response analysis with VAR models. VAR(4) is not chosen as the optimal model until we consider the elimination of the autocorrelation of the residual and compare the LR test value with the chi-square value. Our findings show both positive and negative responses as described in Figures 3 and 4. The variation of stock indices in China has negative responses to the variation of food commodity future prices. In contrast, the variation of food commodity future prices has positive responses to the variation of both stock indices. 

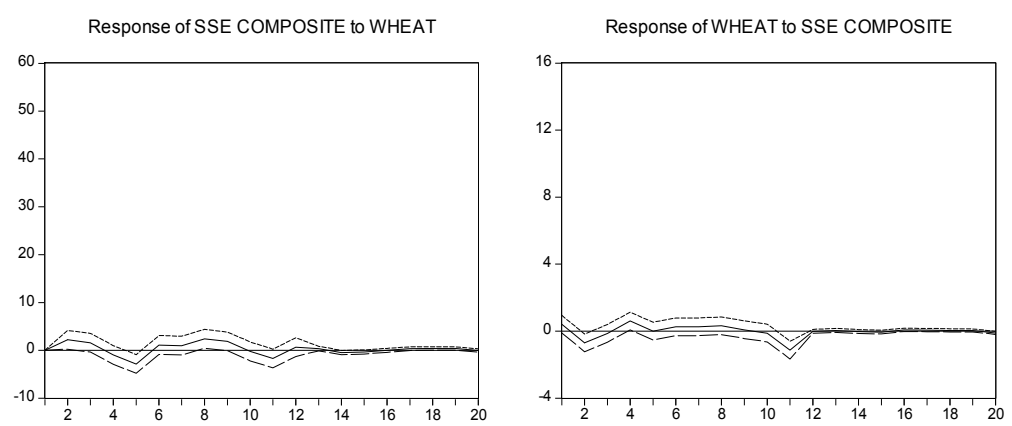

Response of SSE COMPOSITE to CORN

Response of CORN to SSE COMPOSTIE

Response of SSE COMPOSITE to SOYBEAN
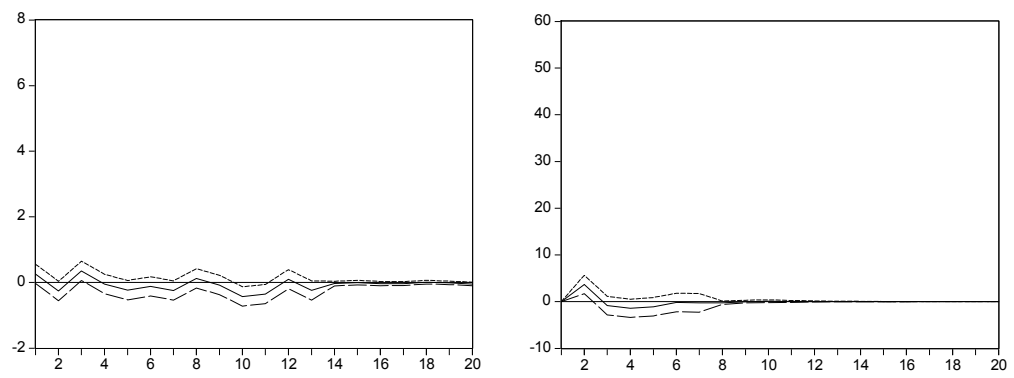

Response of SOYBEAN to SSE COMPOSITE

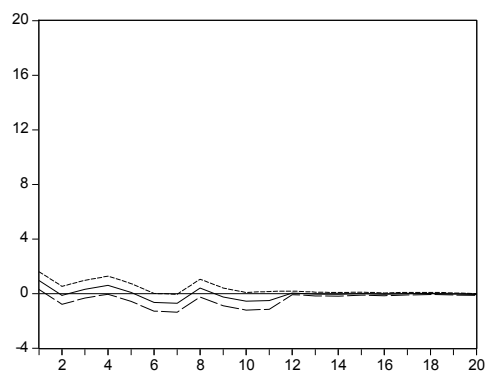

Response of SSE COMPOSITE to SOYBEAN OIL

Response of SOYBEAN OIL to SSE COMPOSITE
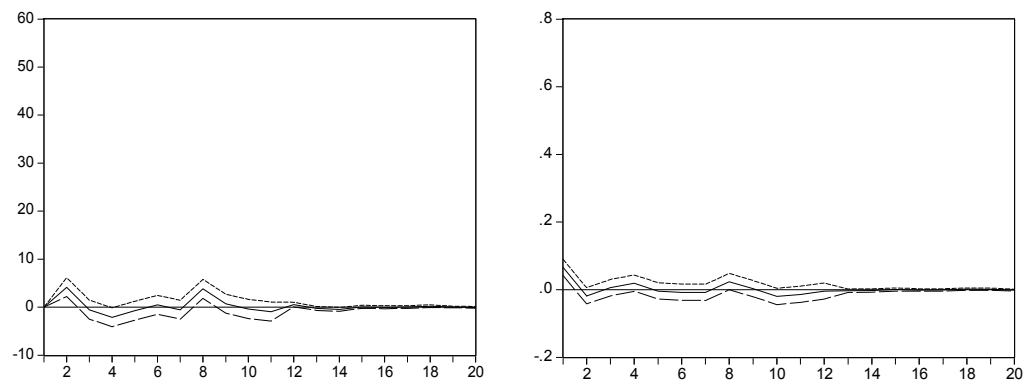

Response of ROUGHRICE to SSE COMPOSITE

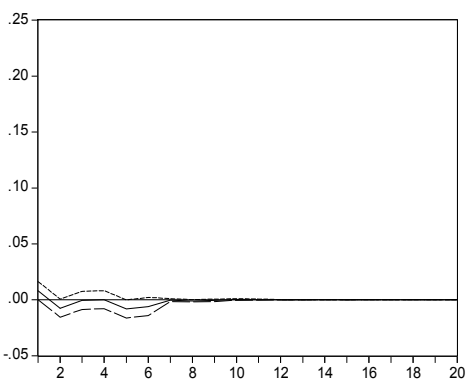

Figure 3. Impulse-responses with granger casual relation for sse composite

Note: Axis X Denoting Lag Length (Trading Day) and Axis Y Denoting the Level of Change (Solid lines show mean performance while dotted lines and dashed lines show upper and lower bound, respectively) 
Response of SZSE COMPONENT to WHEAT

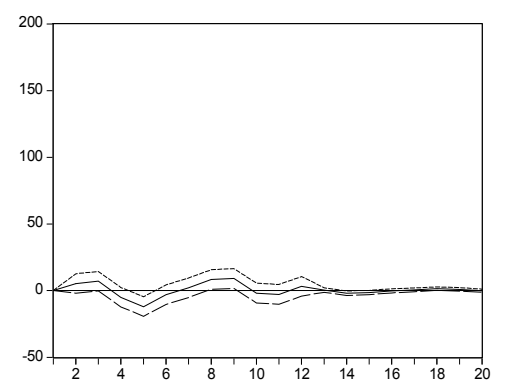

Response of CORN to SZSE COMPONENT

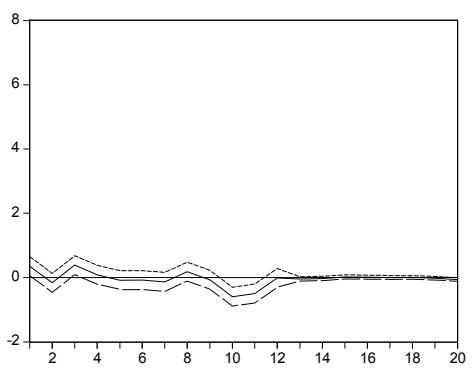

Response of SZSE COMPONENT to SOYBEAN OIL

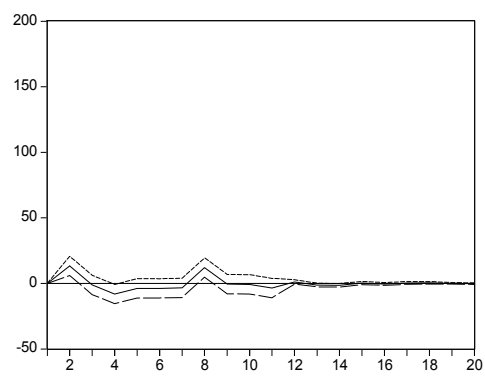

Response of WHEAT to SZSE COMPONENT

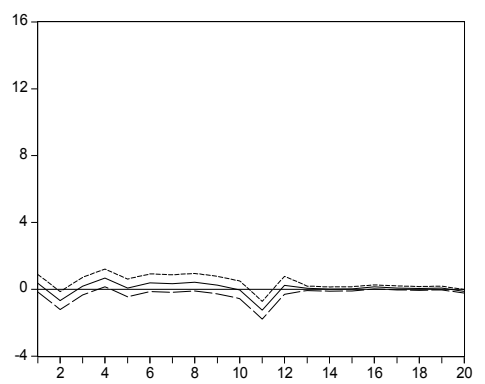

Response of SZSE COMPONENT to SOYBEAN

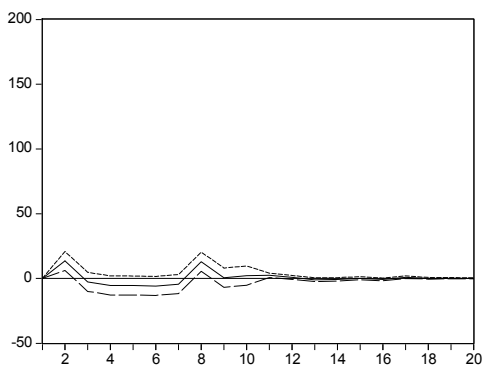

Response of SOYBEAN OIL to SZSE COMPONENT

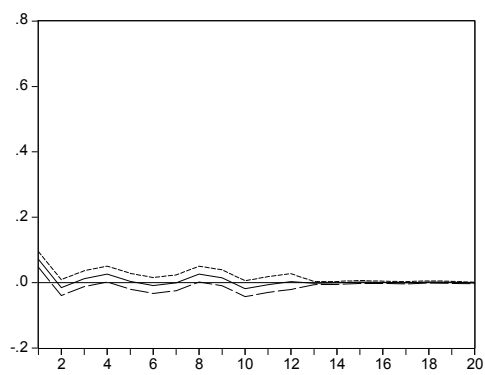

Response of SZSE COMPONENT to CORN

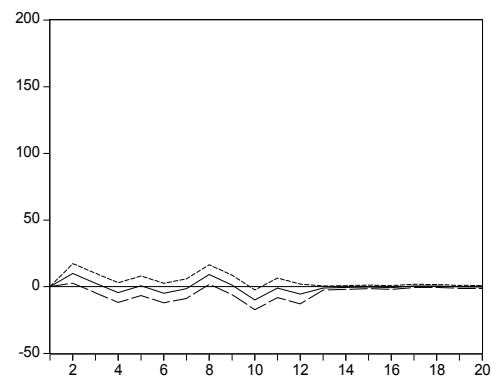

Response of SOYBEAN to SZSE COMPONENT

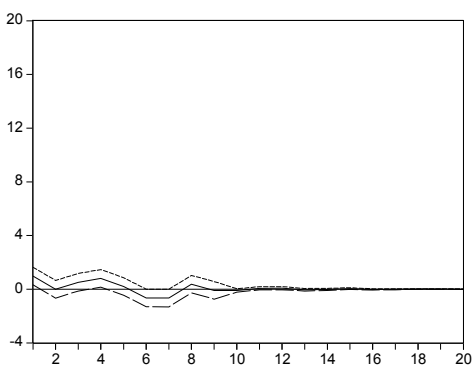

Response of ROUGHRICE to SZSE COMPONENT

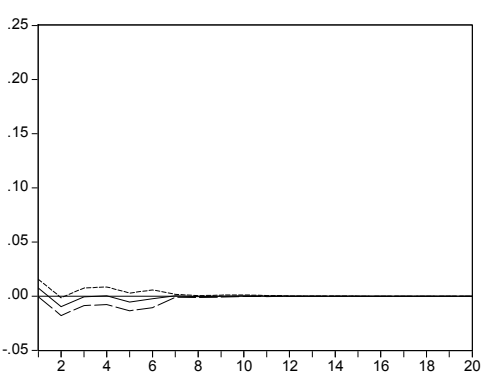

Figure 4. Impulse-responses with granger casual relation for SZSE component

Note: with Axis X Denoting Lag Length (Trading Day) and Axis Y Denoting the Level of Change (Solid lines show mean performance while dotted lines and dashed lines show upper and lower bound, respectively).

\section{Conclusion}

We investigate Granger causal relationships between international food commodity futures and Chinese stock market indices. We analyze the variation of major food commodity futures prices, including wheat, corn, soybean, soybean oil, and rough rice, with the stock indices from two main stock exchanges, SSE Composite and SZSE Component. Our findings show that there exist bilateral Granger cause relationships between most of the food futures prices and both stock indices except for rough rice. Rough rice has a unilateral Granger causal relation with both stock indices. We further carry out impulse-response analysis with Granger causal relationships. Both stock indices show negative responses to the increase in food futures prices, including wheat, corn, soybean, and soybean oil. On the other hand, all food futures prices, including wheat, corn, soybean, soybean oil, and rough rice, show positive responses to the increase in stock price indices for both Shanghai and Shenzhen stock markets.

The results of impulse-response analysis are quite consistent with what happens in China nowadays. China consumes and produces a huge amount of food commodities, including wheat, corn, soybean, and soybean oil, studied herein for various purposes such as human consumption, livestock feed, and ethanol production. It means that food prices are one of important factors affecting inflation in China. Rising food prices increases the inflation rate, thus resulting in a bearish stock market, a negative shock to the economy. 
However, only rice might be different, because its consumption is not as huge as wheat or other food commodities in China. Therefore, rising rice prices does not have an obvious impact on the stock price indices. On the other hand, rising stock price indices is generally one of indicators of economic expansion. The expansion is usually accompanied by inflation, leading to an increase in food prices, which is also supported by the empirical results in this study.

While our results provide support for the close relationship between food prices and stock market indices, they also put this claim in perspective: the stock indices employed in this study are aggregate stock prices, and only aggregate effects can be explained. Further research in this area may break down an aggregate stock index into more specific industries or consider environmental variables together. An interesting extension can account for providing a deeper understanding on China's position in the global food market.

\section{Acknowledgements}

The authors thank an editor and an anonymous referee of this journal as well as seminar participants at Sustainable Asia Conference in Incheon, South Korea for their valuable comments. Financial support from Taiwan's National Science Council is gratefully acknowledged (NSC102-2410-H-009-045 and NSC 102-2221-E-009-079).

\section{References}

Akaike, H. (1987). Special section factor analysis and AIC. Psychometrika, 52, 317-332. http://dx.doi.org/10.1007/BF02294359

Babula, R., \& Somwaru, A. (1992). Dynamic impacts of a shock in crude oil price on agricultural chemical and $\begin{array}{llll}\text { fertilizer } & \text { prices. } & \text { Agribusiness, } & \text { 243-252. }\end{array}$ http://dx.doi.org/10.1002/1520-6297(199205)8:3<243::AID-AGR2720080305>3.0.CO;2-K

Chan, K. (1992). A further analysis of the lead-lag relationship between the cash market and stock index futures market. Review of Financial Studies, 5, 123-152. http://dx.doi.org/10.1093/rfs/5.1.123

Dickey, D. A., \& Fuller, W. A. (1979). Distribution of the estimators for autoregressive time series with a unit root. Journal of the American Statistical Association, 74, 427-431.

Dickey, D. A., \& Fuller, W. A. (1981). Likelihood ratio statistics for autoregressive time series with a unit root. Econometrica, 49, 1057-1072. http://dx.doi.org/10.2307/1912517

Diouf, J. (2007). UN warns of food price unrest. Financial Times. Retrieved from http://www.ft.com/cms/s/0/1f0d4c6a-5ca1-11dc-9cc9-0000779fd2ac.html?nclick_check=1

Du, X., Yu, C. L., \& Hayes, D. J. (2009). Speculation and volatility spillover in the crude oil and agricultural commodity markets: A Bayesian analysis. Working Paper 09-WP 491, Center for Agricultural and Rural $\begin{array}{lllll}\text { Development, } & \text { Iowa } & \text { Sate } & \text { University. } & \text { Retrieved }\end{array}$ http://www2.econ.iastate.edu/research/webpapers/paper_13066.pdf

Fama, E. F., \& French, K. R. (1987). Commodity futures prices: Some evidence on forecast power, premiums, and the theory of storage. Journal of Business, 60, 55-73. http://dx.doi.org/10.1086/296385

Finnerty, J. E., \& Park, H. Y. (1987). Stock index futures: Does the tail wag the dog. Financial Analysts Journal, 43, 57-61. http://dx.doi.org/10.2469/faj.v43.n2.57

Gorton, G., \& Rouwenhorst, K. G. (2004). Facts and fantasies about commodity futures. Financial Analysts Journal, 62, 47-68. http://dx.doi.org/10.2469/faj.v62.n2.4083

Granger, C. W. J. (1981). Some properties of time series data and their use in econometric model specification, Journal of Econometrics, 16, 121-130. http://dx.doi.org/10.1016/0304-4076(81)90079-8

Granger, C. W. J., \& Newbold, P. (1974). Spurious regressions in econometrics. Journal of Econometrics, 2, 111-120. http://dx.doi.org/10.1016/0304-4076(74)90034-7

Harris, L. (1989). The October 1987 S \& P500 stock futures basis. Journal of Finance, 44, 77-99.

Hsiao, C. (1981). Autoregressive modeling and money-income causality detection. Journal of Monetary Economics, 7, 85-106. http://dx.doi.org/10.1016/0304-3932(81)90053-2

Huang, J., Qiu, H., \& Scott, R. (2008). More pain ahead for China's food prices. Far Eastern Economic Review, $171,8-13$.

IPCC. (2007). Climate change 2007: Impacts, adaptation, and vulnerability. Contribution of Working Group II to the Third Assessment Report of the Intergovernmental Panel on Climate Change, Cambridge: Cambridge 
University Press.

Johnson, R., \& Soenen, L. (2009). Commodity prices and stock market behavior in South American countries in the short run. Emerging Markets Finance and Trade, 45, 69-82. http://dx.doi.org/10.2753/REE1540-496X450405

Kawaller, I. G., Koch, P. D., \& Koch, T. W. (1987). The temporal price relationship between S\&P 500 futures and the S\&P 500 index. Journal of Finance, 42, 1309-1329.

NBSC. (2008). International statistical yearbook, various years. Beijing: China Statistical Press.

$\mathrm{Ng}$, N. (1987). Detecting spot forecasts in futures prices using causality tests. Review of Futures Markets, 6, 250-267.

Onour, I., \& Sergi, B. (2011). Modeling and forecasting volatility in the global food commodity prices. Agricultural Economics, 57, 132-139.

Phillips, P. C. B., \& Perron, P. (1988). Testing for a unit root in time series regression. Biometrika, 75, 335-46. http://dx.doi.org/10.1093/biomet/75.2.335

Rosegrant, M. (2008). Impact of biofuel policy on developing country agriculture and food security. Paper presented on the American Agricultural Economics Association Conference, Orlando.

Rosen, D. H., Rozelle, S., \& Huang, J. (2004). Roots of competitiveness: China's evolving agriculture interests. Washington, D.C.: Institute for International Economics.

Siqueira, E. L., Stosic, T., Bejan, L., \& Stosic, B. (2010). Correlations and cross-correlations in the Brazilian agrarian commodities and stocks. Physica A-Statistical Mechanics and Its Applications, 389, 2739-2743. http://dx.doi.org/10.1016/j.physa.2010.01.040

Stoll, H. R., \& Whaley, R. E. (1990). The dynamics of stock index and stock index futures returns. Journal of Financial and Quantitative Analysis, 25, 441-468. http://dx.doi.org/10.2307/2331010

Tse, Y. (1999). Price discovery and volatility spillovers in the DJIA index and futures markets. Journal of Futures Markets, $\quad$ 19, 911-930. http://dx.doi.org/10.1002/(SICI)1096-9934(199912)19:8<911::AID-FUT4>3.0.CO;2-Q

Uri, N. D. (1996). Crude-oil price volatility and agricultural employment in the USA. Applied Energy, 54(5), 353-373.

Yang, J., Qiu, H., Huang, J., \& Rozelle, S. (2008). Fighting global food price rises in the developing world: The response of China and its effect on domestic and world markets. Agricultural Economics, 39, 453-464. http://dx.doi.org/10.1111/j.1574-0862.2008.00351.x

\section{Copyrights}

Copyright for this article is retained by the author(s), with first publication rights granted to the journal.

This is an open-access article distributed under the terms and conditions of the Creative Commons Attribution license (http://creativecommons.org/licenses/by/3.0/). 